\title{
Sensitivity to ultraviolet radiation in a dominantly inherited form of xeroderma pigmentosum
}

\author{
F PAULA IMRAY, ATHEL HOCKEY*, WENDY RELF, \\ ROBERT G RAMSAY, AND CHEV KIDSON \\ From the Queensland Institute of Medical Research, Brisbane 4006; and "King Edward Memorial Hospital \\ for Women, Perth 6001, Australia.
}

SUMmary An Australian family is described in which a mild form of xeroderma pigmentosum (XP) is inherited as an autosomal dominant trait. Studies of lymphoblastoid cells and fibroblasts from affected persons demonstrated cellular sensitivity to ultraviolet (UV) light as judged by diminished clonogenicity and higher frequencies of UV induced chromosome aberrations compared to normal controls. After UV irradiation of dominant XP cells, replicative DNA synthesis was depressed to a greater extent than normal and the level of UV induced DNA repair synthesis was lower than that in normal cells. The level of sister chromatid exchanges and the numbers of 6-thioguanine resistant mutants induced by UV irradiation were equal to those found in normal controls. Although two subjects in the family had skin cancers, this dominant form of $\mathrm{XP}$ is not apparently associated with high risk, or large numbers, of skin cancers in affected persons.

Xeroderma pigmentosum is usually characterised by autosomal recessive inheritance, and obligate heterozygotes are clinically normal ${ }^{1}$ although they may have a higher incidence of skin cancer than random controls. ${ }^{2}$

A dominant pattern of inheritance of a mild form of XP was described in a family in Scotland, ${ }^{3}$ but no further cases of dominantly inherited XP have been described since then.

We describe an Australian family in which a mild form of XP is inherited in an autosomal dominant pattern. Studies in vitro demonstrated sensitivity to UV light in cells from these patients and a reduced capacity for DNA repair synthesis.

\section{Case reports}

The family consisted of a brother and sister each with an affected son and daughter. Affected people were documented for the previous four generations and totalled 21 in all, comprising 11 males and 10 females. There were seven miscarriages recorded in the family history and a number of cases of epilepsy (fig 1).
CASE 1

The proband (IV.17), born on 15.1.43, had three years of sterility after her marriage followed by three miscarriages in the ensuing year. She then had a son in 1966 and a daughter in 1967. The mother and both children were clinically affected with XP. Skin lesions developed in early childhood and on examination she had freckles in a collar distribution and on the trunk and axilla but not on the face. Her skin was dry and there were no café-au-lait spots, but she had tiny pin point haemangiomata scattered over her trunk and limbs which had developed when she was pregnant.

CASE 2

Her son (V.11) had a collar of freckles, a large number of freckles on the trunk, some dark brown naevi 1 to $2 \mathrm{~cm}$ in diameter, one café-au-lait spot on his thigh, several depigmented spots 1 to $2 \mathrm{~cm}$ in diameter, and axillary freckles. His soft palate was slightly more pigmented than the hard palate, his nails had several transverse white lines and spots, and his skin was excessively dry.

CASE 3

The proband's daughter (V.10) had thick reddish hair. She had freckles in a collar distribution and on 


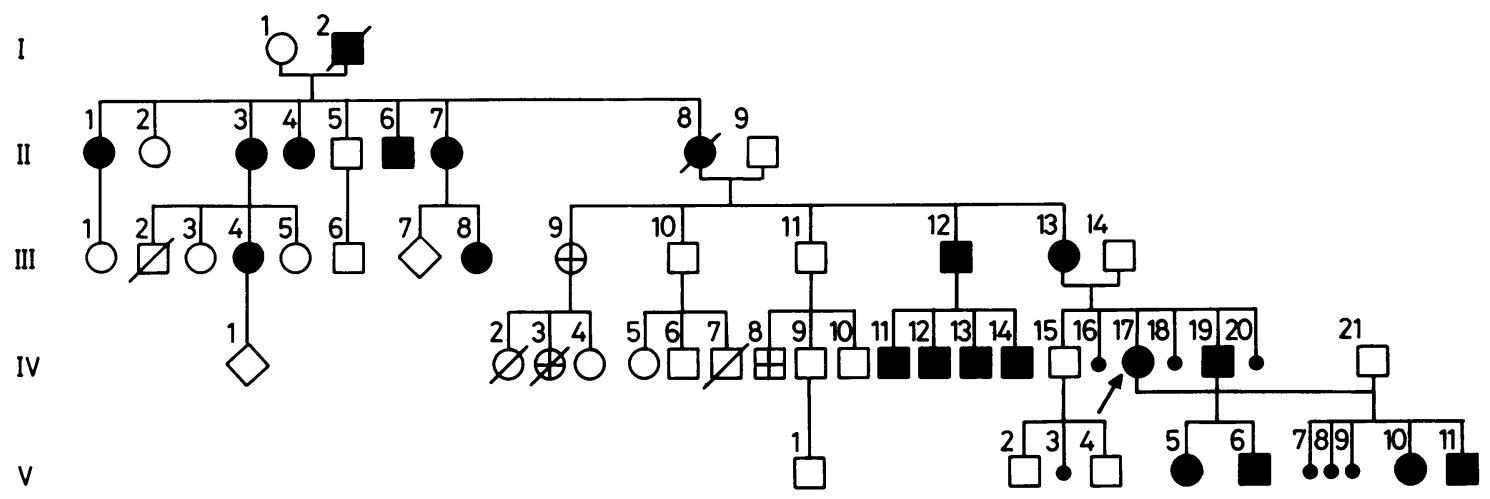

FIG 1 Pedigree of proband's family. Shaded symbols show affected subjects with xeroderma pigmentosum. III.13 and IV.17 had basal cell carcinoma and melanoma respectively.

the trunk and limbs, although she had a clear face like her mother and brother. There were four large and three small café-au-lait spots, axillary freckles, white patches on the nails (one of which was depigmented), and a very dry skin.

CASE 4

The brother of the proband (IV.19) had excessively dry, almost scaly skin with heavy freckling over the entire trunk and a brown sunburn type pigmentation on his arms and legs which tended to mask the freckles, although a collar distribution was still evident. The facial skin was clear. There were two or three definite café-au-lait spots among the freckles and a $4 \mathrm{~cm}$ diameter brown naevus over the lumbosacral area. His eyes and hair were dark.

CASE 5

The daughter of case 4 (V.5) had similar features with dark facial pigmentation and dark hair with a reddish area in the occipital region. Freckling was extensive, including axillary freckling, and there were generalised areas of brown and depigmented skin, some clearly demarcated and some vaguely delineated. Her skin was moderately dry. She had behavioural difficulties thought to be unrelated to her skin pathology.

CASE 6

The son of case 4 (V.6) had dark eyes, very pale skin, and reddish hair. There was rather indistinct generalised pigmentation and depigmentation was quite marked with freckling. He had two well defined lesions: one $4 \times 5 \mathrm{~cm}$ speckled, almost piebald lesion in the left groin, near a large, brown, darkly pigmented naevus on the upper thigh. He had pigmentary change in his axilla and very dry skin.

Age of onset was only established in the offspring (V.10, V.11) of the proband (IV.17) when she recalled that her daughter (V.10) had presented as a very young baby with an olive skin and depigmentation over her abdomen, whereas her son had not shown any abnormal features until he was a toddler but exhibited a more severe response to sun exposure than his sister. The proband's mother (III.13) and her brother (III.12) were examined and found to be similarly affected. Photographs are presented in a group, each with a characteristic dermatological feature in the particular member (fig 2).

The following malignancies have been noted. III.13 had a $1 \mathrm{~cm}$ basal cell carcinoma removed in 1982 at the age of 70 . The proband herself had a melanoma and II. 6 died of cancer of the lung. Recurrent infections occurred in II.4, while II. 5 had a son who was blind with a detached retina. Although café-au-lait lesions are hallmarks of neurofibromatosis there was no evidence of this disease in any members of the family. The clinical and familial characteristics are consistent with a mild form of XP with dominant inheritance (DXP).

\section{Materials and methods}

CELL LINES

Epstein-Barr virus transformed lymphoblastoid cell lines were derived from peripheral blood lymphocytes as described previously. ${ }^{4}$ Skin fibroblast lines (DXP62F and DXP63F) were obtained from subjects IV.17 and IV.19 respectively. All cell lines were diploid and cultures were demonstrated to be free of Mycoplasma. ${ }^{5}$ 


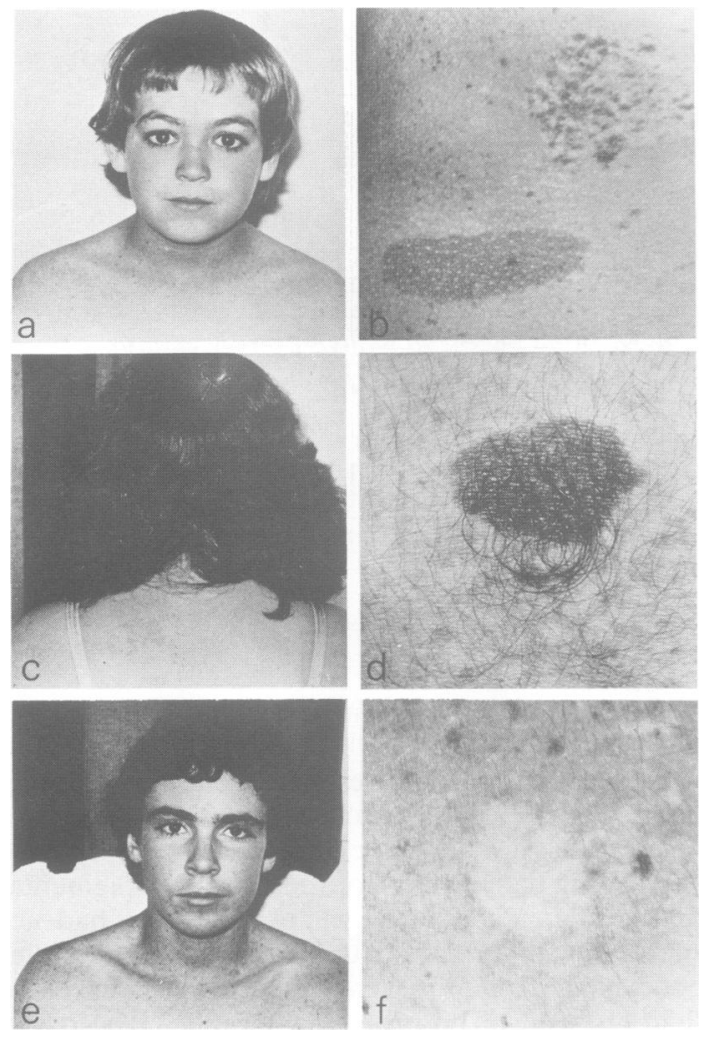

FIG 2 Dermatological features in members of the family. (a) V.6, face and collar with freckles. (b) V.6, piebald patch. (c) V.10, café-au-lait spot centralised in a generalised depigmented area. (d) IV.19, melanotic freckle. (e) V.17, typical 'dark face' as in V.6. (f) V.5, depigmented naevus.

Cell lines DXP62ABR, DXP63ABR, and DXP64ABR were established from subjects IV.17, IV.19, and V.5 respectively. Other lymphoblastoid cell lines used in this study were normal controls C10ABR, C16ABR, C17ABR, XPA (XP301ABR), XPD (GM2253), and a Fanconi's anaemia line GM4510 (obtained from the Human Genetic Mutant Respository, Camden, New Jersey, USA). XPA fibroblasts (XP301F) were also used.

UV SENSITIVITY

Methods used to determine DNA repair synthesis, unscheduled DNA synthesis, DNA replication, and cellular sensitivity to UV irradiation have been described previously. ${ }^{6}$

SISTER CHROMATID EXCHANGES AND CHROMOSOME ABERRATIONS

Metaphase cells were harvested 24 hours after irradiation or other treatments by addition of colcemid to a final concentration of $0.1 \mu \mathrm{g} / \mathrm{ml}$ for two hours. The cells were treated for 15 minutes with $0.075 \mathrm{mmol} / \mathrm{l} \mathrm{KCl}$ and fixed in methanol:glacial acetic acid (3:1). For chromosome studies cells were stained with $5 \%$ Giemsa and for differential staining of sister chromatids the method of Perry and Wolff was followed.

\section{UNSCHEDULED DNA SYNTHESIS IN} HETEROKARYONS

Fibroblast lines were used in these experiments. Approximately $10^{5}$ cells were incubated overnight with carboxylated microspheres (Polysciences Inc, Warrington, Pennsylvania, USA). Red fluorescing microspheres of $1.44 \mu \mathrm{m}$ diameter and uncoloured microspheres of $0.5 \mu \mathrm{m}$ diameter were used at a ratio of $\sim 10$ microspheres/cell. The difference in size between these microspheres facilitates identification of heterokaryons. Cells were washed free of media containing beads; trypsinised, mixed, and then allowed to reattach to coverslips. Cell fusion was induced by exposure to $50 \%$ polyethylene glycol (PEG) $/ 10 \%$ dimethyl sulphoxide (DMSO) in RPMI 1640 for one minute followed by dilution and washing (PEG MW4000, Fluka AG, Buchs, Switzerland; DMSO, BDH Chemicals Ltd, Poole, England; RPMI 1640 medium, GIBCO, New York, USA). Cells were irradiated with $40 \mathrm{Jm}^{-2} \mathrm{UV}$ six hours after fusion, and growth medium containing $10 \mu \mathrm{Ci} / \mathrm{ml}\left({ }^{3} \mathrm{H}\right)$ thymidine (Amersham International, Amersham, England) was added. After two hours incubation at $37^{\circ} \mathrm{C}$, coverslips were washed with PBS and attached to slides. Slides were coated with Kodak emulsion and held at $4^{\circ} \mathrm{C}$ in the dark for a week before developing and staining with toluidine blue. Grains over non-S phase nuclei were counted under a $100 \times$ oil immersion objective.

\section{UV INDUCED MUTAGENESIS}

Mutagenesis following UV irradiation was measured using the method of Albertini et al. ${ }^{8}$ The frequency of 6-thioguanine resistant $\left(6 \mathrm{TG}^{\mathrm{R}}\right)$ cells was measured in cultures exposed to varying doses of UV irradiation and grown for 15 days after irradiation to allow expression of induced mutations. The $6 \mathrm{TG}^{\mathrm{R}}$ cells were detected by autoradiography as those incorporating $\left({ }^{3} \mathrm{H}\right)$ thymidine in media containing $40 \mu \mathrm{g} / \mathrm{ml}$ 6-thioguanine.

\section{Results}

\section{UV SENSITIVITY}

Lymphoblastoid cell lines (LCL) were established from members of the family and fibroblast cultures were derived from two of these subjects. LCLs from 
XP patients reflect the UV sensitivity exhibited by the patient's fibroblasts. ${ }^{9}$

Determination of UV sensitivity by formation of colonies in agar demonstrated abnormal sensitivity of these DXP cell lines compared to normal controls (fig 3a). The mean Do value for controls was 4.5 $\mathrm{Jm}^{-2}$ while DXP62ABR and DXP63ABR had Do values of 2.9 and $2 \cdot 3 \mathrm{Jm}^{-2}$ respectively. Fibroblasts from these affected subjects were also more sensitive to UV than controls (fig $3 b$ ).

Results obtained by counting cells excluding the dye trypan blue at three days and four days after irradiation confirmed the increased sensitivity to UV killing of these DXP cell lines compared to normal cell lines (data not shown).

(a)

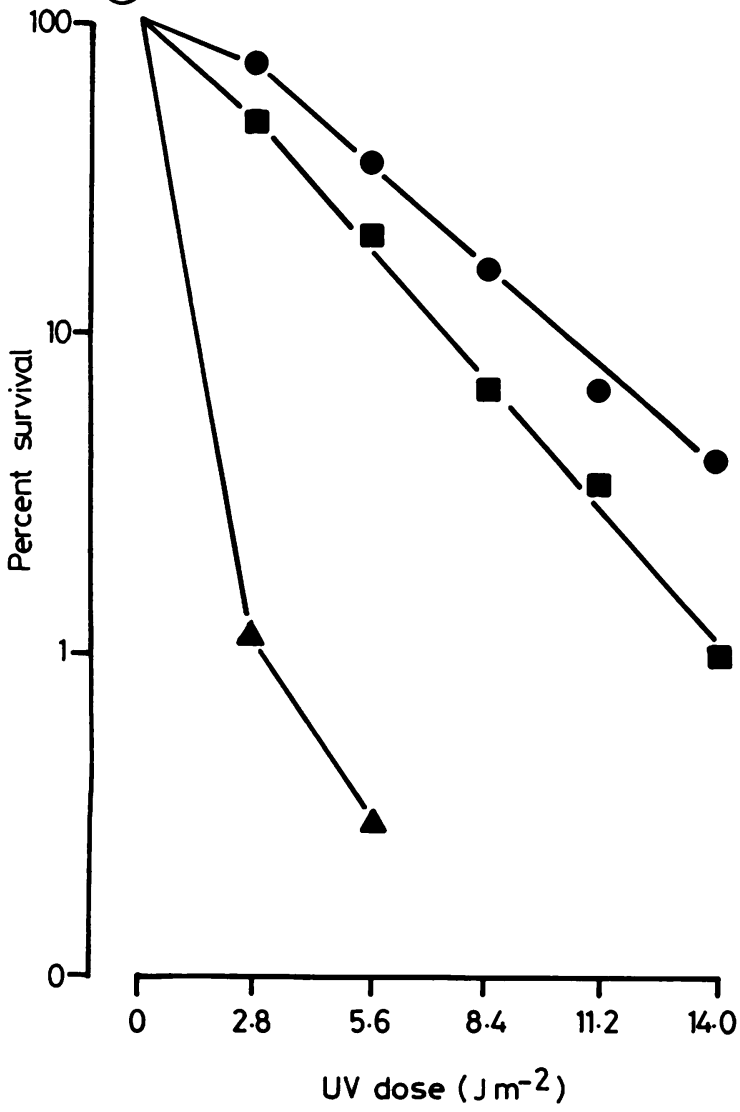

REPLICATION AFTER UV EXPOSURE

After exposure to low doses of UV light, DNA replication is inhibited in excision deficient and variant XP cells, Cockayne's syndrome cells, and familial melanoma cell lines to a greater extent than in normal cells. ${ }^{61011}$ The rates of DNA replication in DXP and normal cells are shown in fig 4 , after irradiation with $5 \mathrm{Jm}^{-2}$. The DXP cells showed more marked depression of the rate of DNA synthesis two hours after irradiation and recovered more slowly than normal cells.

DNA REPAIR SYNTHESIS

DNA repair synthesis can be measured in UV irradiated cells as $\left({ }^{3} \mathrm{H}\right)$ thymidine incorporation in

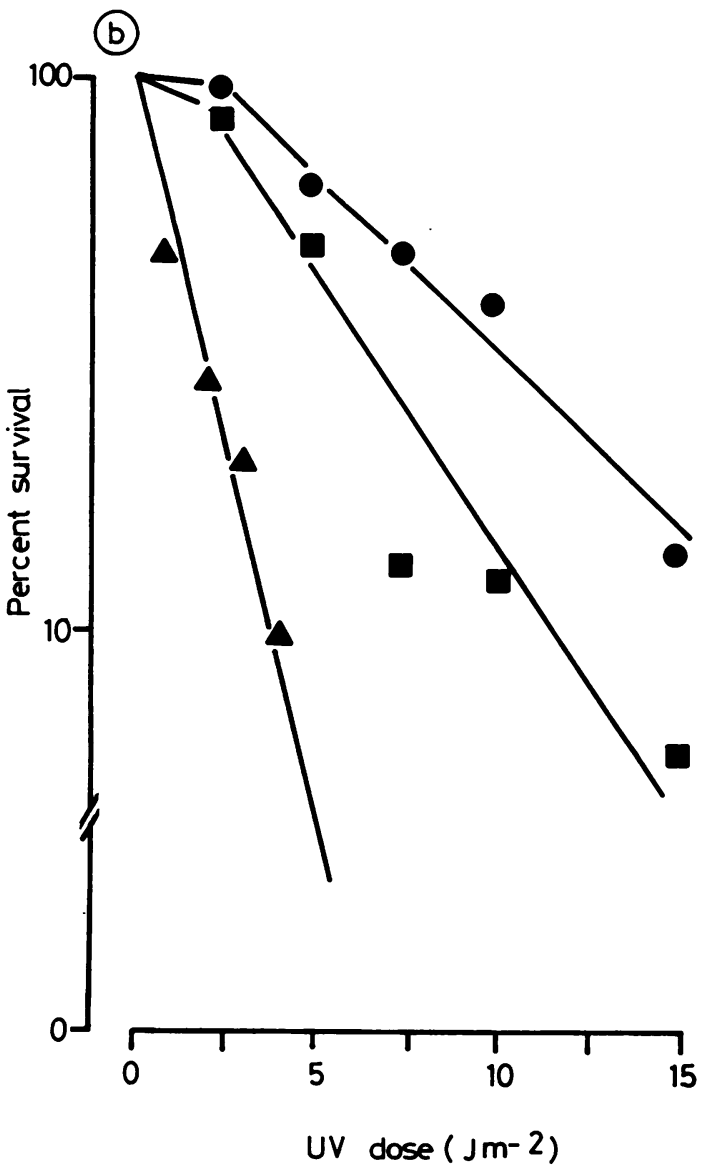

FIG 3 (a) Survival of lymphoblastoid cell lines after UV irradiation measured by colony formation in agar. Control CON16ABR ; DXP63ABR ם; GM2253 (XPD) $\Delta$. (b) Survival of fibroblasts after UV irradiation, measured

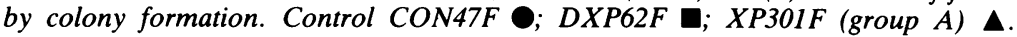




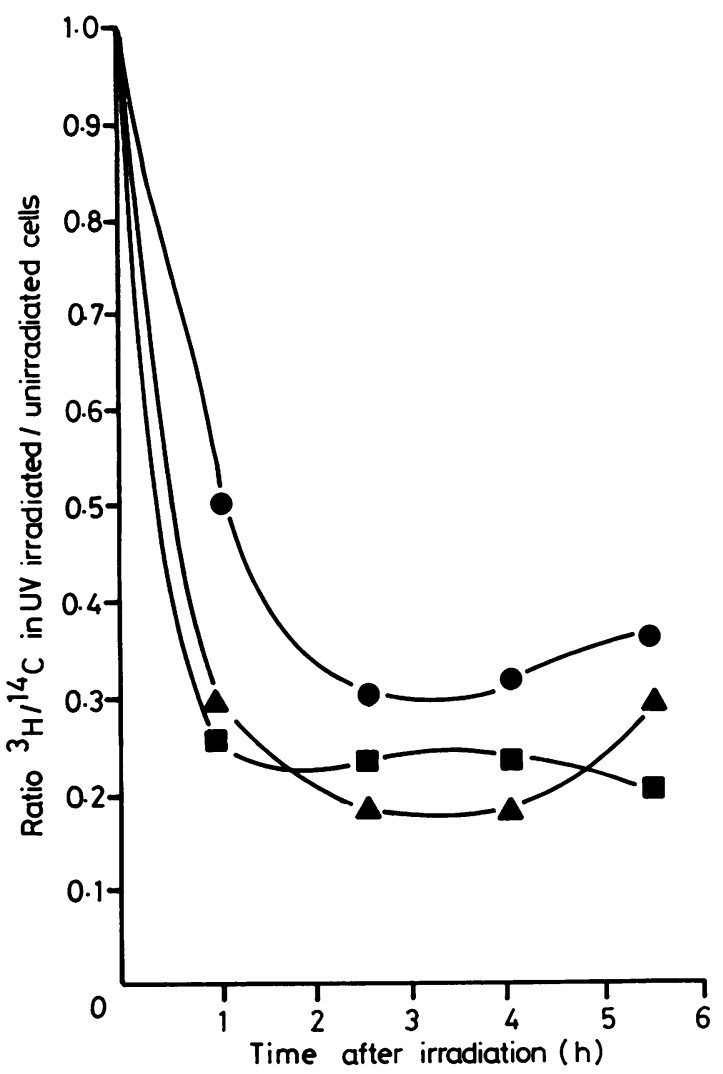

FIG 4 Inhibition of replication following UV irradiation (5 $\mathrm{Jm}^{-2}$ ). The percentage of control value is calculated from the ratio of pulsed $\left({ }^{3} \mathrm{H}\right)$ thymidine incorporation in $U V$ irradiated cells, compared to that incorporated in the corresponding non-irradiated cells at various times after exposure to $U V .\left({ }^{3} \mathrm{H}\right)$ thymidine incorporation was standardised against $\left({ }^{14} \mathrm{C}\right)$ thymidine labelled DNA in each cell culture. The ratio immediately after irradiation (time 0) has been designated as 1.0. Control C17ABR O; $D X P 62 A B R \square ; D X P 63 A B R \triangle$.

the presence of hydroxyurea, an inhibitor of replicative DNA synthesis. ${ }^{6}$ Results obtained in the two hour period immediately after irradiation showed that DXP cells performed only $64 \%$ of the amount of repair synthesis carried out by normal cells (data not shown).

UNSCHEDULED DNA SYNTHESIS

Autoradiographic determination of unscheduled DNA synthesis does not require use of inhibitors such as hydroxyurea. The mean number of grains per nucleus in non-S phase cells was determined for normal cells and DXP62F fibroblasts. During a two hour incubation with $10 \mu \mathrm{Ci} / \mathrm{ml}\left({ }^{3} \mathrm{H}\right)$ thymidine following UV irradiation, DXP cells performed $58 \%$ of the amount of unscheduled DNA synthesis which normal cells carried out in this period (table 1). This value is similar to that obtained above by measuring $\left({ }^{3} \mathrm{H}\right)$ thymidine incorporation in the presence of hydroxyurea by liquid scintillation counting.

\section{SISTER CHROMATID EXCHANGES}

The frequency of SCE per cell was determined in the presence of $10 \mu \mathrm{g} / \mathrm{ml} \mathrm{BrdU}$, with and without exposure to UV light. The frequencies of SCE with BrdU alone were three to five per cell in all cell lines examined. This is in the range previously reported for spontaneous SCE in LCLs. ${ }^{61213}$ The frequencies of SCE 48 hours after UV irradiation were normal (fig 5).

\section{CHROMOSOME ABERRATIONS}

The frequencies of chromosome aberrations induced in lymphoblastoid cells after exposure to 4 $\mathrm{Jm}^{-2} \mathrm{UV}, 80 \mathrm{rad}^{60} \mathrm{Co} \gamma$ irradiation, mitomycin $\mathrm{C} 0.5$ $\mu \mathrm{g} / \mathrm{ml}$ for 24 hours, or 4-nitroquinoline oxide 0.4 $\mu \mathrm{g} / \mathrm{ml}$ are listed in table 2 . In comparison with normal controls, DXP cell lines only showed statistically significant $(p<0.01)$ sensitivity to the UV mimetic chemical 4-nitroquinoline oxide, although

TABLE 1 Unscheduled DNA synthesis in fibroblasts incubated with $10 \mu \mathrm{Ci} / \mathrm{ml}\left({ }^{3} \mathrm{H}\right)$ thymidine for 2 hours following $40 \mathrm{Jm}^{-2} \mathrm{UV}$ irradiation.

\begin{tabular}{llc}
\hline Cell line & \multicolumn{2}{l}{ Grains per nucleus (mean $\pm S E M)$} \\
\cline { 2 - 3 } & Unirradiated & $40 \mathrm{Jm}^{-2}$ \\
\hline CON47F & $1 \cdot 7 \pm(0 \cdot 1$ & $22 \cdot 1 \pm 1 \cdot 4$ \\
DXP62F & $3 \cdot 2 \pm(0 \cdot 4$ & $15 \cdot( \pm \pm 1 \cdot 1$ \\
\hline
\end{tabular}

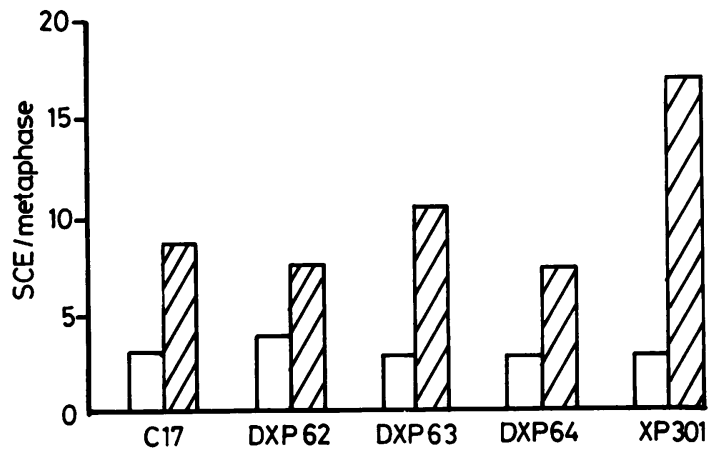

FIG 5 The frequencies of sister chromatid exchanges per metaphase in lymphoblastoid cell lines in the presence of $10 \mu \mathrm{g} / \mathrm{ml} \mathrm{BrdU}$ with $\square$ and without $\square$ exposure to 4 $\mathrm{Jm}^{-2}$ UV light. 
higher than normal frequencies of aberrations were induced by UV and MMC.

UV INDUCED MUTAGENESIS

UV induced mutability of DXP62ABR and DXP63ABR was similar to that in normal controls (data not shown), in contrast to the high mutability of XPA and XP variant cells.

UDS IN HETEROKARYONS

Although it is not possible to complement this DXP with the recessively determined XP complementation groups, cell fusion studies were done to determine if the defect in UDS would be dominant in heterokaryons formed after fusion to normal cells. DXP62F fibroblasts were allowed to incorporate $0.5 \mu \mathrm{m}$ diameter microspheres and normal fibroblasts given $1.44 \mu \mathrm{m}$ microspheres. This enabled unfused cells, homokaryons of both parental lines, and heterokaryons to be unequivocally identified. Since the microspheres tend to cluster around the nucleus it is possible to determine the origin of each nucleus in many heterokaryons. It was found that UV irradiation immediately after fusion induced lower levels of repair synthesis than in unfused cells. However, if the mixture of fused cells was incubated for six hours between fusion and UV irradiation similar values were obtained. The mean numbers of

TABLE 2 Frequencies of chromosome and chromatid aberrations per metaphase in lymphoblastoid cells 24 hours after exposure to DNA damaging agents.

\begin{tabular}{llllll}
\hline Treatment & \multicolumn{3}{l}{ Cell line } & & \\
\cline { 2 - 6 } & C16ABR & C17ABR & DXP62ABR & GM2253 & GM4510 \\
\hline Gamma $80 \mathrm{rad}$ & 0.28 & 0.39 & 0.33 & $\mathrm{ND}$ & ND \\
UV $8 \mathrm{Jm}^{-2}$ & 0.16 & 0.22 & 0.33 & 0.44 & ND \\
MMC $0.5 \mu \mathrm{g} / \mathrm{ml}$ & 0.23 & 0.28 & 0.36 & 0.24 & 2.40 \\
4NQO $0.4 \mu \mathrm{g} / \mathrm{ml}$ & 0.18 & 0.30 & 0.60 & 1.12 & 1.66 \\
\hline
\end{tabular}

Fifty metaphase spreads scored for each determination. Comparisons between DXP and control lines were carried out by $\chi^{2}$ test. ND $=$ not determined.

TABLE 3 Unscheduled DNA synthesis in fibroblasts prelabelled with Polysciences microspheres measured by grains per nucleus in autoradiographs after 2 hours incubation with $10 \mu \mathrm{Ci} / \mathrm{ml}\left({ }^{\overline{3}} \mathrm{H}\right)$ thymidine.

\begin{tabular}{llll}
\hline & \multicolumn{2}{l}{$\begin{array}{l}\text { Grains per nucleus } \\
\text { (mean } \pm \text { SEM) }\end{array}$} \\
\cline { 2 - 4 } & Not fused & Homokaryon & Heterokaryon \\
\hline Unirradiated controls & & & \\
CON47F (large beads) & $2 \cdot 8 \pm 0 \cdot 2$ & $2 \cdot 8 \pm 0.2$ & $3 \cdot 0 \pm 0 \cdot 3$ \\
DXP62F (small beads) & $2 \cdot 5 \pm 0 \cdot 2$ & $3 \cdot 0 \pm 0 \cdot 3$ & $3 \cdot 1 \pm 0.3$ \\
$40 m^{-2}$ UV & & & \\
CON47F (large beads) & $25 \cdot 0 \pm 1 \cdot 2$ & $19 \cdot 3 \pm 1 \cdot 4$ & $13 \cdot 7 \pm 0.7$ \\
DXP62F (small beads) & $17 \cdot 5 \pm 0 \cdot 8$ & $14 \cdot 0 \pm 0.7$ & $13 \cdot 3 \pm 0.6$ \\
\hline
\end{tabular}

grains per nucleus for unfused cells, homokaryons, and heterokaryons six hours after fusion are shown in table 3. In heterokaryons formed between normal and DXP fibroblasts the defect in UDS appeared to be dominant.

\section{Discussion}

In this family a mild form of XP is inherited in a pattern consistent with an autosomal dominant trait, with close to $100 \%$ penetrance. Of the 32 subjects at risk (offspring of one affected parent) for the disorder 20 are affected. Both males and females are affected and males can transmit the disorder to their sons, excluding an $\mathrm{X}$ linked gene. The features of the disorder are marked xeroderma, generalised dark pigmentation, excessive freckling, and severe erythema in response to sunlight.

Skin cancer is not common in this family. Although the proband had a melanoma removed and her grandmother had a basal cell carcinoma no other affected members have reported skin cancers.

An autosomal dominant inheritance of predisposition to multiple skin cancers in exposed facial skin has been described by Cleaver. ${ }^{14}$ Fibroblasts from affected subjects showed no defects in excision repair, as are found in the various groups of classical $\mathrm{XP}$ and in the present family.

The XP complementation groups $F$ and $G$ are reported not to have skin cancer, ${ }^{1}$ although skin cancers occur frequently in other complementation groups ( $A$ to $E$ ) and variants. This dominantly determined XP is most similar to the recessive $\mathrm{XP}$ complementation group $\mathrm{E}$ which consists of one kindred with relatively mild clinical symptoms and no neurological abnormalities. ${ }^{15}$ Fibroblasts from group $\mathrm{E}$ have 40 to $60 \%$ of normal UV induced unscheduled DNA synthesis, similar to the levels in cell lines from DXP subjects.

Cellular abnormalities in classical XP cells after UV irradiation include decreased cell survival, increased chromosome breakage, a higher frequency of SCE and, in some cases, an increased yield of mutations. This dominant form of XP has some of these characteristics: decreased cell survival, reduced DNA repair synthesis, and increased chromosome breakage, the latter being more pronounced in response to the radiomimetic 4 NQO. However, UV induced SCE and mutations were not raised compared to normal controls. Thus, the dominant XP reported here represents a distinct entity which must be added to the compendium of xeroderma syndromes.

We wish to thank Dr Peter Randall who made the diagnosis and referred the family to us, and the 
Directors of MHS and King Edward Memorial Hospital for Women under whose auspices the clinical studies were undertaken. Studies at the Queensland Institute of Medical Research were supported by grants from the National Health and Medical Research Council of Australia and the Queensland Cancer Fund.

\section{References}

' Kraemer KH. Xeroderma pigmentosum. In: Dermis DJ, Dobson RL, McGuire J, eds. Clinical dermatology. New York: Harper and Row, 1980:1-33.

2 Swift M, Chase C. Cancer in families with xeroderma pigmentosum. J Natl Cancer Inst 1979;62:1415-26.

3 Anderson TE, Begg, M. Xeroderma pigmentosum of mild type. Br J Dermatol Syph 1950;62:402-7.

4 Chen PC, Lavin MF, Kidson C, Moss D. Identification of ataxia telangiectasia heterozygotes: a cancer prone population. Nature 1978;274:484-6.

${ }^{5}$ Russell WC, Newman C, Williamson DH. A simple cytochemical technique for demonstration of DNA in cells infected with mycoplasmas and viruses. Nature 1975;253:461-2.

${ }^{6}$ Ramsay RG, Chen P, Imray FP, Kidson C, Lavin MF, Hockey A. Familial melanoma associated with dominant ultraviolet radiation sensitivity. Cancer Res 1982;42:2909-12.

7 Perry P, Wolff S. New Giemsa method for the differential staining of sister-chromatids. Nature 1974;251:156-8.

${ }^{8}$ Albertini RJ, Castle KL, Borcherding WR. T-cell cloning to detect the mutant 6-thioguanine-resistant lymphocytes present in human peripheral blood. Proc Natl Acad Sci USA 1982;79:6617-21.
${ }^{9}$ Andrews AD, Robbins JH, Kraemer KH, Bucll DN. Xeroderma pigmentosum long-term lymphoid lines with increased ultraviolet sensitivity. J Natl Cancer Inst 1974;53:691-3.

10 Rude JM, Friedberg EC. Semi-conservative deoxyribonucleic acid synthesis in unirradiated and ultraviolet-irradiated xeroderma pigmentosum and normal human skin fibroblasts. Mutat Res 1977;42:433-42.

1 Lehmann AR, Kirk-Bell S, Mayne L. Abnormal kinetics of DNA synthesis in ultraviolet light-irradiated cells from patients with Cockayne's syndrome. Cancer Res 1979:39:4237-41.

${ }^{12}$ Cheng WS, Tarone RE, Andrews AD, Whang-Peng JS, Robbins JM. Ultraviolet light-induced sister chromatid exchanges in xeroderma pigementosum and in Cockayne's syndrome lymphocyte cell line. Cancer Res 1978;38:1601-9.

13 Tohda M, Moraguchi K, Takahashi K, Oikawa A, Matsushima T. Epstein-Barr virus-transformed human lymphoblastoid cells for study of sister chromatid exchanges and their evaluation as a test system. Cancer Res 1980;40:4775-80.

${ }^{14}$ Cleaver JE. An autosomal dominant inheritance for multiple sunlight-induced malignancy in a patient without abnormalities in DNA repair or replication. Cytogenet Cell Genet 1981;29. $122-4$.

15 Kraemer KH, De Weerd-Kastelein EA, Robbins JM, et al. Five complementation groups in xeroderma pigmentosum. Mutat Res 1975;33:327-40.

Correspondence and requests for reprints to Dr F P Imray, Queensland Institute of Medical Research, Bramston Terrace, Herston, Brisbane 4006, Australia. 